\title{
Unknown Tumor Zone
}

National Cancer Institute

\section{Source}

National Cancer Institute. Unknown Tumor Zone. NCI Thesaurus. Code C160198.

An indication that the tumor zone is unknown. 